\title{
Las relaciones literarias entre Cataluña y Rumanía
}

\author{
LOURDES SÁNCHEZ RODRIGO \\ (Universidad de Granada) \\ 1sanchez@ugr.es \\ Recibido: diciembre de 2013. Aceptado: gebrero de 2014
}

\begin{abstract}
Resumen: Aproximación a las relaciones histórico-literarias entre escritores catalanes y escritores rumanos desde la Edad Media hasta nuestros días, así como la recepción de sus obras en los países respectivos.
\end{abstract}

Palabras clave: Rumanía. Cataluña. Historia y Literatura

\begin{abstract}
An approach to historical-literary connection between Catalan writers from Medieval Ages up to the present, as well the receipt or their work in the corresponding countries.
\end{abstract}

Keywords: Romanian. Catalan. Historical-literary.

A lo largo de los dos últimos siglos, la literaturas rumana y catalana, han sido bastante desconocidas por otras literaturas románicas, según M. a Ángeles Ciprés Palacín, en el caso de la primera, porque «La lengua rumana no fue siempre admitida como lengua románica; su incorporación a este ámbito, al menos en Francia, data de los inicios del siglo XX (...) debido fundamentalmente a la variedad léxica que presenta, en la que los términos eslavos dominan» (Ciprés 2003:141), o, como escribe Joaquín Garrigós, a que «propiamente dicha no nace hasta el siglo XIX (...) nacimiento de la propia Rumanía como estado, que también tiene lugar en la segunda mitad del siglo XIX» (Garrigós 2006: 1). En el caso catalán, aunque no podemos hablar de Cataluña como estado, sí podemos decir que también es, a mediados del siglo XIX, cuando, como en Rumanía, se produjo el despertar nacional de la misma manera que la recuperación de su literatura después de varios siglos en que, por muy diversas razones, prácticamente, dejó de cultivarse. Otras circunstancias históricas similares las ponen en esta situación de desconocimiento general también en el siglo XX. Dos conflictos bélicos, la segunda guerra mundial y el posterior régimen comunista en Rumanía, la guerra civil española y la dictadura franquista en Cataluña y, en ambos casos, las consecuencias del exilio y, en palabras de Lluís Duch a propósito de Mircea Eliade, el sometimiento al «terror de la historia»: «No hay que perder de vista que en buena medida la trágica historia de su patria, Rumanía, una pequeña nación, deter- 
mina de forma decisiva el sentido de su obrar y de su pensar. Rumanía, como otras naciones del este de Europa, ha vivido bajo el «terror de la historia», es decir, bajo el dictado de la historia que hacían las grandes potencias. Desde esta perspectiva, la vida y la obra de Eliade ofrecen aspectos muy interesantes para la interpretación de nuestra realidad nacional, ya que, de alguna manera, la subsistencia de la nación catalana se ha visto también sometida al «terror de la historia»» (Duch 1983: 8). A todo esto, deberíamos añadir que, en el siglo XX, el conocimiento de la literatura rumana en otras lenguas tuvo una dificultad más porque: «el món romanès, com tot el món comunista, interessava poc a Europa $i$ aquí encara molt menys tal i com estàvem en efersvescència del nacional catolicisme» (Duch 1983: 9). Ambas literaturas, por lo tanto, tuvieron que recuperarse del desfase cultural que sufrieron una vez superados esos periodos de totalitarismo y, aunque son hechos que van más allá de lo puramente literario, nos pueden ayudar a entender no sólo su destino común, a pesar de su lejanía geográfica, sino también muchos de los rasgos que las caracterizaron.

Pocas son las alusiones a Rumanía y a su literatura en la cultura catalana, no sólo porque el primer documento escrito en rumano que se conoce es de 1521 y el primero impreso es de 1559, el catecismo de Coresi, sino porque, en el occidente románico, como ha explicado la profesora Eugenia Popeanga (1992: 159-170), la cultura rumana se ha manifestado y se ha comunicado a través no sólo de una lengua románica sino también del eslavo y el griego ${ }^{1}$, lo que si, por un lado, ha dado lugar a que participe de las características de los dos mundos culturales (Popeanga 1992: 162) teniendo contactos con el bizantino, por otro, la ha alejado del común territorio románico. No obstante, las referencias a los vlacos y a los territorios que hoy son la actual Rumanía las encontramos en algunos textos medievales catalanes como, por ejemplo, en la novela Tirant lo Blanc del valenciano Joanot Martorell, en donde se narran la conquista y los asentamientos catalanes en Oriente. Así, el caudillo rumano, contemporáneo de Martorell, János Húnyadi, voivoda de Hungría y vencedor sobre los turcos en 1448 y 1456, se convierte en modelo de Tirant. Según ha escrito el profesor Ribera Llopis en su interesantísimo trabajo dedicado a la presencia de los Balcanes en la cultura catalana (Ribera 1999: 91):

muchos datos, amén de las emblemáticas victorias, aproximan el personaje novelesco al histórico. Por ejemplo: János, por valaco, fue llamado Balachus, voz mantenida en occidente como Blach o, por deformación, Blanch en catalán, (...). Las victorias de «lo comte Blanch» se celebraron en Valencia y Barcelona. El personaje era conocido y Joanot Martorell pudo sumarse a esa mitomanía: su caballero, liberador de Constantinopla, llevará un cuervo en su bandera como lo llevaba el escudo de armas de Húnyadi, y ante su próxima muerte se hará atender espiritualmente por su confesor, un franciscano, siendo de la misma orden el religioso que está en 1456 junto al lecho de muerte de

1 Cultura griega que siguió teniendo mucha influencia en la rumana en la edad moderna, por ejemplo, en el siglo XVIII, cuando las tierras rumanas estuvieron dominadas por el Imperio Otomano. El poeta Alecu Vacarescu escribió canciones de amor siguiendo la tradición del poeta Anacreonte. 
János Húnyadi. El voivoda en cuestión circuló por entre la literatura catalana como reflejo de aquella fama.

De la misma manera, como señala Ribera Llopis siguiendo a Isabel de Riquer, donde en el anónimo «Plors, Plants, senglots e gemechs de congoxa, complant» sobre la caída de Constantinopla, se alude a «lo Blanch ros», hay que entender que se trata de János Húnyadi (Riquer 1997: 76).

Otro texto catalán, la Crónica de Ramon Muntaner, dedica unos capítulos a las batallas de catalanes y aragoneses contra turcos y griegos. Su autor, el mismo Muntaner, escribe sobre Blaquia («la terra més forta del món») lo que nos lleva a situar a las huestes de Roger de Flor en la actual Rumanía, aunque este dato fue desmentido, en 1777, por el erudito Francesc de Montcada que, al leer, en la crónica, que «Roger de Flor: tenía también la mejor fama en Romania y en todo el mundo» (cap.199), sostiene que, en dicha expedición, lo que los catalanes atravesaron fue la parte montañosa de la provincia de Thesalia llamada Blaquia, denominación que abarcaba el Imperio Griego o de Constantinopla, correspondiéndose con la Tracia, la antigua Macedonia y parte de Asia Menor, y no Vlaquia. En definitiva, según escribe Montcada, «a la Valaquia no llegaron los nuestros con cien leguas» (Montcada 1777: 340).

De todas maneras, hasta no hace mucho tiempo, con el fin de sostener la relación entre Cataluña y Rumanía, se ha seguido manteniendo la localización rumana de la crónica de Muntaner. Así lo hizo Nicolae Iorga, que, en su obra Algunos días por España, al hablar de la lengua catalana escribe que «esta lengua ha dado, en prosa y en poesía -juglares por una parte, por otra la Crónica de Ramón Muntaner, que habla de nuestra «Valaquia» balcánica al referirse a las proezas catalanas» (Ortega 2003: 158). El mismo Iorga, en 1921, se interesó también, como documento para la historia balcánica, por otro texto catalán, anónimo, la Història de Jacob Xalabín (a.1404), «relato de impronta oral que cruza datos tergiversados de las crónicas turcas con motivos folklóricos y de la ficción caballeresca y sentimental, para llevarnos al final al escenario de Kossovo en 1389, 1387 en el documento» (Ribera 1999: 91).

Cuando en el siglo XIX se produjo el resurgimiento rumano con las revoluciones de 1821 y 1848 , la unión de los Principados Rumanos de 1859 y la definitiva Guerra de la Independencia de 1877 después de la guerra con el Imperio Otomano, en Cataluña, como ya hemos dicho, se estaba iniciando un fenómeno similar que, en la historiografía catalana, se conoce con el nombre de Renai$x e n c ̧ a$. En los dos territorios el sentimiento común por la patria renacida que, por otra parte, era algo absorbente en cualquier caso de nacionalismo romántico lo veremos concretarse, por una parte, en una poesía surgida a partir de la mitificación romántica del pasado -esa imagen histórica ideal de la Edad Media- y, por otra, en el interés por recuperar el patrimonio cultural en el que se inscribía ese pasado. Así, se llevan a cabo estudios y recopilaciones de textos y tradiciones populares, como medio para reconstruir los rasgos específicos de la mentalidad y la cultura de la nación, que hicieron, por ejemplo, los escritores Vasile Alecsandri (1821-1890) o Mihai Eminescu (1850-1889), —el poeta nacional por excelencia de Rumanía y padre de la lengua rumana moderna según Iorga—, que, en 
sus propios poemas, hunden sus raíces en las tradiciones y el folklore de su país, y, en el caso catalán, de manera paralela, escritores y eruditos de la Renaixença, como, por ejemplo, Marià Aguiló o Manuel Milà i Fontanals, además de llevar a cabo una importante labor filológica de recolección de materiales lingüísticos y literarios tradicionales, componen un tipo de poesía estrechamente vinculada al descubrimiento de la poesía nacional y popular. La propia lengua era, por tanto, según la ideología romántica de todos ellos, el mejor vehículo de expresión para expresar el espíritu o el alma de sus respectivos pueblos.

Al otro lado de los Pirineos, también en el último tercio del siglo XIX, se estaba produciendo un fenómeno equivalente. Un grupo de intelectuales, encabezado por Josèp Romanilha y Frederic Mistral, muy bien relacionados con el movimiento catalán de la Renaixença, reivindicaba un cierto renacimiento regionalista occitano. Mistral, autor del Mireio, y los felibres eran invitados a Cataluña y colaboraban en los Jocs Florals. Buen ejemplo de esa magnífica relación es la dedicatoria «als catalans de França» con que Jacint Verdaguer abre su poema épico Canigó (1886). Sin embargo, contrariamente a lo que estaba pasando en Cataluña, el movimiento occitano de los primeros años no pasó de ser un regionalismo idealista, monárquico y muy inconcreto a nivel político, en definitiva un tradicionalismo basado en la sociedad patriarcal y rural que, en sus fiestas literarias, reclamaba, como mucho, una confederación latina cultural, pero sin la carga ideológica que, por esa misma época, tenían los Jocs Florals catalanes.

Lo que sí podemos confirmar es que, a partir de aquella época, el movimiento felibre mantuvo una estrecha relación con la literatura rumana, a raíz, sobre todo, de la celebración, en Montpellier, de unos encuentros internacionales en donde participaron escritores catalanes, italianos y rumanos, las llamadas Fiestas Latinas, que, en la celebración del año 1878, tuvo como protagonista al poeta rumano Vasile Alecsandri ganador del primer premio literario del certamen con el poema La canción del latino, en la misma línea de reivindicación de la raza latina que había hecho Mistral. Este poema apareció en una publicación menor, catalana, editada en Estados Unidos, La llumanera de Nova York (8/1878 p.3), junto a un artículo dedicado al autor, Alecsandri, y al premio que se le había concedido en Montpellier, en donde se comentan las relaciones que se habían establecido entre Rumanía y los pueblos del mediodía reunidos en el hogar de hermandad de la raza latina (Ciprés 2003: 143). De todas maneras, meses antes, y traducido al español, Teodor Llorente lo había publicado en el periódico valenciano La Mañana (30/6/1878).

Otro dato de interés sobre los contactos culturales entre Rumanía y Provenza es el de la correspondencia que la reina Isabel de Rumanía, conocida con el seudónimo de Carmen Sylva, mantuvo con varios escritores franceses y occitanos. El centenario del nacimiento de Mistral en 1930, cuando una delegación rumana viajó hasta Avignon para asistir a la inauguración del monumento del poeta y, asimismo, la aparición de una revista trilingüe, occitano-francesa-rumana, emprendida por Eugène Tanase en 1955, año del Centenario del Mirèio, mantuvieron, aunque fuera simbólicamente, en aquellos años, los puentes culturales de diálogo entre ambas comunidades culturales (Ciprés 2003: 147). 
En esta época, en Rumanía, aparece un renovado interés, muy cosmopolita, por lo que, culturalmente, estaba pasando en Occidente, y la situación catalana, tan relevante por el conflicto de afirmación nacional que vivía, como ya hemos dicho muy similar al rumano, se miraba con cierta simpatía. Como explica Mircea Angehlescu (2006: 277), a mitad del siglo XIX, viajar al extranjero, y en concreto a España, un país que se revelaba bajo el aspecto más romántico, se puso de moda. Los rumanos querían ser cosmopolitas, conocer otras culturas y España se convertía para ellos en una meta, como lo había sido para otros viajeros europeos de la época o, incluso, años atrás, para los ilustrados de su propio país como Dinicu Golescu (1777-1830) que viajó por Europa a principios del XIX. Los rumanos, cuando visitaban España, subrayaban las semejanzas propias de dos naciones aún preindustriales y buscaban, en sus orígenes, circunstancias paralelas que los acercaran. Así lo hizo Mihail Kogalniceanu cuando subrayaba que Rumanía y España tenía un patrimonio común grecolatino y oriental, turco en los rumanos, árabe en los españoles, que ejercía hondas influencias en ambos pueblos que todavía persistían. Además de señalar esta característica de cruce entre lo latino y lo oriental, Kogalniceanu hacía observaciones históricas o caracteriológicas entre las dos naciones y escribía sobre las diferentes etnias que convivían en ambos territorios, como la gitana por ejemplo, o sobre sus comidas o sus elementos maravillosos y primitivos. Es decir, ponía atención en todo lo que era peculiar frente a la uniformidad de las naciones modernas. Anghelescu transcribe el siguiente texto de Kogalniceanu (Anghelescu 2006: 279):

A pesar de todo ni los alemanes con sus fondas, con sus camas, con sus ciencias, ni Francia con sus albergues, con sus fricassées y sus tortillas no me gustan tanto como España, con sus carencias... este país, quizá porque se parece al mío, me gusta con sus horizontes, con sus bandidos, con la falta de confort, con sus campesinos simples y amables, con los hombres de sociedad, con sus tradiciones y cuentos que encuentras a cada paso, con sus mendigos, sus grandes boyardos, me gusta y no cesa de encantarme.

Juan M. Ribera Llopis, en un trabajo inédito que ha puesto amablemente a mi disposición titulado Notícies i traduccions catalano-romaneses al llindar del Nou-cents, hace una relación exhaustiva de la recepción de las letras contemporáneas catalanas en la cultura de aquel país durante el siglo XIX y ofrece, además, una valiosa bibliografía. El primer autor catalán, documentado, traducido al rumano, escribe Ribera Llopis, fue Ángel Ruiz i Pablo (1865-1927), un poeta menor. Pronto, sin embargo, se comenzaron a reseñar textos más firmes y de mayor peso literario como la novela de Narcís Oller (1846-1930) La Papallona (1882), traducida al rumano en 1900, a la que seguirán otros títulos del mismo autor, como L'escanyapobres (1884), traducciones, por otro lado, de las que parece ser Narcís Oller nunca tuvo noticia.

Cuando en 1902 muere Jacint Verdaguer, sigue diciendo Ribera Llopis, la prensa rumana informa sobre el luctuoso hecho con diversas notas necrológicas, en las que se comenta la trayectoria verdagueriana como poeta nacional catalán, haciendo hincapié, lógicamente, en su poema épico L’Atlàntida (1877), sin dejar 
de relacionarlo con el movimiento provenzal liderado por Frederic Mistral, muy conocido en Rumanía por su amistad con Vasile Alecsandri como hemos dicho anteriormente. A Verdaguer hay que añadir los nombres de Maragall, Costa i Llobera o Joaquim Ruyra, Prudenci Bertrana o Rusiñol, que, también, fueron objeto de estudio y traducción a principios ya del siglo XX, de la misma manera que otros intelectuales contemporáneos como Ramon Vinyes, Pere Coromines, Josep Carner, Carles Soldevila o Josep Maria de Sagarra, y, de manera muy destacada, Eugeni d'Ors, aunque, quizá, más el d'Ors en español que en catalán.

Traducir al rumano obras literarias en otros idiomas, como, por ejemplo, el catalán, era «primordial vehicle operatiu», en palabras, de nuevo, de Ribera Llopis, para salir del reducto de la literatura folclórica. Y es, precisamente, en este terreno de la traducción donde adquiere especial relevancia la figura del escritor, crítico, humanista y erudito Nicolae Iorga que visitó España por primera vez durante diez días en la primavera de 1927 (Ortega 2003:152). Del País Vasco a Andalucía y de Andalucía a Cataluña, sus impresiones y experiencias dieron lugar a una serie de conferencias que pronunció sobre España en el Teatro Nacional de Bucarest ese mismo año y que más tarde recogió en su libro Câteva zile prin Spania (1927) en donde subrayó la semejanza de lo español y lo rumano en carácter e historia como habían hecho antes que él los viajeros del XIX (Anghelescu 2006: 282). Pero Iorga ya no es el observador romántico que detalla con detenimiento todo lo que va viendo y viviendo, sino que, en sus crónicas, «sugiere más que describe» (Ortega 2003: 153) y, sobre todo, tiende a romper con la tradición decimonónica de los textos ingleses, franceses y alemanes cuando se referían a España.

Por lo que respecta a la literatura catalana, Iorga demuestra una gran erudición. Autor del libro en rumano Contributiuni catalane la istorie bizantina (1927), con edición catalana de 1961 con el título Ramon Muntaner i l'imperi bizantí, conocedor también, como ya hemos dicho, de la Història de Jacob Xalabín o de la Crònica de Muntaner, es también un excelente y apasionado traductor, sobre todo a partir de 1930, de poetas del siglo XIX como Maragall o de coetáneos como Sagarra. Iorga escribe también sobre las circunstancias sociales y políticas que, en esta época, está viviendo Cataluña, aunque, frente a las reivindicaciones catalanistas, sostiene que «la tierra es la misma que en el resto de la Península» (Ortega 2003: 157) e, incluso, acusa al catalanismo de debilidad subrayando la unión nacional española. Como escribe Juan José Ortega Román, a pesar de la fragmentación histórica de España, Iorga lo hace como «un claro alegato en defensa de la unión de los Principados Rumanos» (2003: 157). Pero el intelectual rumano (Ortega 2003: 158), buen conocedor de la literatura catalana, no puede ocultar a sus lectores que:

es verdad que un largo desarrollo histórico, todavía no representado en monumentos $^{2}$, ha precedido a la situación actual. Tan verdad como que una dulce

2 Es, al menos, curiosa, esta afirmación de Iorga sobre la ausencia de monumentos propiamente catalanes, cuando él, en aquella época, era buen amigo del arquitecto catalán Josep Puig i Cadafalch. 
lengua, más cercana a la provenzal que a la castellana, se habla aquí y en las inmediaciones rurales que hay hasta el Ebro; tan verdad como que esta lengua ha dado, en prosa y en poesía - juglares por una parte, por otra la Crónica de Ramón Muntaner, que habla de nuestra «Valaquia» balcánica al referirse a las proezas catalanas - obras remarcables (...). De este movimiento ha resultado, no obstante, para la humanidad, el renacimiento de una literatura y sobre todo una admirable búsqueda de todo lo que atañe a la patria chica.

Los años en los que Nicolae Iorga visitó España fueron los de la Dictadura de Primo de Rivera, cuando Josep Pla, tan ávido viajero por Europa como el mismo Iorga, llegó a Bucarest tras un pequeño crucero por el Danubio. Seguramente Pla sabía que otro catalán, Josep Pin i Soler, había viajado, en los años 80 del siglo XIX, con espíritu abierto y cosmopolita, alejado de los tópicos románticos, por tierras rumanas, «los límites del continente europeo» (Ribera 2011: 62), y, además, habría leido sus interesantes textos sobre Bucarest. Era el año 1928 y Josep Pla, en calidad de periodista, cubría las corresponsalías de La Publicitat, El Sol o La Veu de Catalunya. De su primera visita a Rumanía no tenemos constancia de que dejara nada escrito, pero sí que lo hizo de la siguiente, la de 1929. Después de un viaje por el Mediterráneo durante los meses de agosto y septiembre, Pla «embarca en Constantinopla en un barco inglés para dirigirse a Constanza y Bucarest y desde allí regresar a Catalu$\tilde{n} a »$. De aquel viaje «escribió treinta y ocho artículos entre octubre de 1929 y enero de 1930» (Badosa 1997: 162), uno de ellos dedicado a las ciudades rumanas en donde había estado. La crónica es más que un reportaje un testimonio personal lleno de pinceladas literarias. Pla, subraya tanto la latinidad de Rumanía: «vivíssima $i$ que ha tingut una resistència admirable a dos mil anys de pressions estranyes i fortíssimes» (Pla 1982: 407) como la eslava. Un país «jove, ric i inèdit» (Pla 1982: 413), en el que todo está por hacer y con una gran diversidad: «una llengua llatina, un fons de sang eslava, un desig de riquesa i de vida moderna» (Pla 1982: 413).

De Constanza, —que le produjo una magnífica impresión: «un poble gran, modern, d'aspecte germànic i centreeuropeu» (Pla 1982: 406) pero que «pràcticament acaba de néixer» (Pla 1982: 406)—, Josep Pla viajó, en tren, hasta Bucarest, «una ciutat enorme, voltada de suburbis inacabables, caòtics, esfondrats», confusa en su estilo, improvisada, que aspira a ser occidental y cosmopolita pero que, según leemos, es todavía agraria y feudal. Una ciudad, en definitiva, que le desagrada y que no corresponde a un país que, cruzado por un río como el Danubio, «impressionant en la seva grandiositat i riquesa», «té una enorme personalitat» que comienza «quan s'ha acabat la darrera habitació miserable de Bucarest» (Pla 1982: 413). La monumentalización del centro de la urbe a imagen de la capital francesa, lo que haría que fuera conocida como «la pequeña París», durante el reinado de Carol I Hohenzollern (1866-1914), un empeño modernizador que continuaron sus sucesores Fernando I y Carol II, parece que no llamó su atención más que en los aspectos negativos de una ciudad construida a grandes impulsos.

En el texto no falta el comentario sociológico que, como siempre en Pla, se sobrepone a la función informativa. El plato que degusta, por ejemplo, en un 
restaurante de Constanza, es una variante de «la carn d'olla» catalana; la manera de vestir de los habitantes le sirve para comparar a la población campesina con «la camisa fora dels pantalons, como els russos; unes calces bombatxes a la turca; unes espardenyes de cordes d'espart i un caftà al cap, més aviat moscovita» (Pla 1982: 411) con el rumano de Bucarest que, cuando se redime de la tierra, «porta un barret flexible, sabates de xarol, un abric amb una pell i una gavardina» (Pla 1982: 412). Pero, como ya se sabe, a Pla todo le servía, en este caso la comida y la indumentaria, porque, para él, cualquier elemento, fuera el que fuese, era tan sintomático y eficaz para explicarnos la realidad como la historia, el arte o la literatura.

Hasta bien entrado el siglo XX las cosas no comenzaron a cambiar en lo que se refiere a la recepción literaria rumana en Cataluña, no sólo por la difusión del gran Mircea Eliade, que junto a Emile (Michel) Cioran, Eugène Ionescu y Brancusi han sido reconocidos como los grandes creadores que Rumanía ha dado al mundo en el siglo XX (Moix 200: 4). Su obra así como la de otros escritores rumanos de igual renombre universal, Tristan Tzara, o Paul Celan, empezó a ser estudiada en profundidad y a traducirse pero no desde el rumano sino desde el francés a otras lenguas, entre ellas la catalana (Motoc 2003: 109), y aunque los libros traducidos al catalán fueron escasos como escribe Diana Motoc en el trabajo citado (2003: 104), sí ayudaron a dar a conocer el ámbito rumano del que, de una u otra manera, se sentían deudores. Rumanía los había visto crecer y en todos había dejado una huella profunda tanto personal como literariamente aunque renegaran de ello en ocasiones. Por ejemplo Cioran reconoció en su obra la influencia del dramaturgo Caragiale y de la poesía popular rumana (Motoc 2003: 98), y Eliade dejó escritas unas palabras muy significativas en las que afirma que «consideraba su propia existencia como el camino azaroso y a veces duro que había de conducirlo desde el exilio a la patria de la identidad» (Motoc 2003: 96).

Por otro lado, los estudios que se han llevado a cabo en España sobre Mircea Eliade siempre han hecho hincapié en su relación con el escritor catalán Eugeni d'Ors «a quien le unirá un sentimiento compartido de amistad y de admiración» (Motoc 2003: 96) hasta el punto de que le llegó a ofrecer su obra en catalán y en español para que fuera traducida al rumano (Diez de Velasco 2006: 6). A su vez, Eliade envió a d'Ors una recopilación de artículos para su publicación en 1934 con el título de Oceanografie, precisamente como había titulado Eugeni d'Ors un libro de 1918, Oceonografia del tedi. Como escribió Diez de Velasco: «Se podría decir que el propio modelo de recopilaciones elidianas de esta época tienen un cierto aire dorsiano» (2006: 4). De hecho, las dos figuras se han llegado a comparar en buen número de aspectos vitales y profesionales, además de los puramente intelectuales, literarios y filosóficos (Díez de Velasco 2007: 102-105). Lo hizo, por ejemplo, Alejandro Cioranescu (1911-1999): «No hay que olvidar (que Eliade) fue también periodista, con un activo de más de 800 artículos de toda índole: actividad comparable, hasta cierto punto, con la de Eugenio d'Ors, y que hizo de él la brújula de la rebeldía cultural conocida en la literatura rumana con el nombre de Nueva Generación» (Díez de Velasco 2007: 82). 
Eliade, que conoció a d'Ors en Madrid en su primer viaje a España a finales de 1941, ya había leído, en francés, la obra del escritor catalán cuando firmaba como Xènius en los primeros años del siglo XX. Autor de libros como Filosofia de l'home que treballa i que juga (1914) e ideólogo de la generación de intelectuales noucentistes, como lo será, años después, en el Bucarest de la década de los 30, el propio Eliade (Díez de Velasco 2007: 91), en 1942 lo describió como:

uno de los hombres de la Europa moderna que me ha interesado (me «ha apasionado») desde hace mucho tiempo. Lo que me gusta de él es lo universal, lo paradójico y lo desigual. Leyendo buena parte de sus libros españoles, me he percatado de su genialidad y de su formidable estilo periodístico; de lo próximo que está a Goethe y, no obstante, qué lejos se ha quedado de él. Como Papini, Huxley, Gide y Unamuno, d'Ors me interesa especialmente por sus defectos, por lo que hay de caduco, de fragmentario e incluso de fáctico en su obra.

Palabras de admiración correspondidas por Eugeni d'Ors en varias de sus glosas en donde reseñó las obras del escritor rumano. Sin embargo, con el tiempo, Mircea Eliade «inseguro de su posición académica (...) Inseguro de lo políticamente correcto de las posiciones ideológicas de d'Ors en los años de la postguerra» (Díez de Velasco 2006: 14), acabó alejándose del intelectual catalán, hasta el punto de que no llevó a cabo el proyecto de traducir al rumano sus obras como habían quedado en su encuentro de Madrid en el verano del 41.

Después de la Segunda Guerra Mundial, del aislamiento cultural europeo de Rumanía durante los cuarenta años de comunismo y aún en la actualidad la trilogía intelectual rumana del siglo XX formada por Cioran, Ionescu i Eliade ha sido más conocida como francesa que como rumana. Como ha escrito Diana Motoc (2003: 94):

La desigualdad creciente en el campo de la traducción a favor del ámbito anglosajón, sobre todo, y de las culturas occidentales en general, en detrimento de las llamadas lenguas exóticas o de las lenguas marginadas histórica, política y económicamente, resulta ser una tendencia evidente en el caso de los autores rumanos, cuya presencia en el espacio editorial español es escasa a pesar de pertenecer a una cultura de raíces latinas.

No ha ocurrido lo mismo con la literatura catalana en Rumanía, sobre todo después de la dictadura de Ceacescu (Balaciu/Montoliu 2003: 166), tiempo en el que «la duresa i l'aïllament polític van fer que la recepció de traduccions catalanes al romanès fos molt menor que a altres països com Hongria, Bulgària o als països de l'antiga unió Soviètica». Los poemas de Espriu, Vinyoli, Gimferrer o los textos de Pere Calders o Mercè Rodoreda como La Plaça del Diamant, traducidos al rumano en 1993, fueron los primeros casos que cristalizaron en un importante proyecto cultural de la editorial Meronia que, en 1998, inauguró una colección de obras catalanas en rumano con estudios introductorios que contextualizaban a los autores traducidos (Balaciu/Montoliu 2003: 168). 


\section{BIBLIOGRAFÍA}

Angehlescu, M. (2006) «Viajeros rumanos en España, en busca de las raíces comunes», Revista de Filología Románica, anejo IV, pp. 277-284

Badosa, C. (1997) Josep Pla. Biografía del solitario, Madrid, Alfaguara.

Balaciu Matei, J./Montoliu, X. (2003) «Traduccions catalano-rumanes: antecedents i present del projecte editorial "Meronia"», Revista de Filología Románica, 20, pp. 163-170.

Ciprés Palacín, Ma Á. (2003) «Un poeta rumano en Provenza», Revista de Filología Románica, 20, pp. 135-150.

Diez de Velasco, F. (2006) «Mircea Eliade (1907-1986) y Eugenio d'Ors (18811954): historia de una mutua admiración», Conferencia presentada en el Instituto Cervantes de Bucarest el 22 de septiembre de 2006: http//webpages. ull.es/users/fradive/confe/bucarestcervantes.

Díez de Velasco, F. (2007) «Mircea Eliade y Eugenio d'Ors (y el arquetipo)», Ilu. Revista de Ciencia de las Religiones, 12, pp. 81-112.

Duch, Ll. (1983) Mircea Eliade. El retorn d'Ulisses a Ítaca, Barcelona, Publicacions de l'Abadia de Montserrat.

Garrigós, J. (2006) Sinopsis de la literatura rumana, www.analitica.com/va/ arte/documentos/9643048.asp.

Moix, Ll. (2000) «Notas para la sinfonía rumana», La Vanguardia (24 de noviembre).

Moncada, F. (1777) Expedición de los catalanes y aragoneses contra turcos y griegos, Madrid.

Motoc, D. (2003) «La traducción y la recepción de M. Eliade, E. M. Cioran y E. Ionescu en España», Quaderns. Revista de traducció, 10, pp. 93-110.

Ortega Román, J. J. (2003) «Nicolae Iorga: viajero por España», Revista de Filología Románica, 20, pp. 151-162.

Pla, J. (1982) «Les escales de Llevant», Obres Completes, XIII, Barcelona, Destino.

Popeanga, E. (1992) «El mundo románico occidental y la historiografía bizantina. Puntos de encuentro», Erytheia, 13, pp. 159-170.

Ribera Llopis, J. M. (1999) «Presencia de los Balcanes en la cultura catalana», Revista de Filología Románica, 16, 85-93.

Ribera Llopis, J. M. (2011) «Díptico viajero: Josep Pin i Soler en Bucarest y en Constantinopla», Revista de lenguas y literaturas catalana, gallega y vasca, 16 , pp. 57-77.

Riquer, I. de (1997) Poemes catalans sobre la caiguda de Constantinoble, edició i estudi, Vic, Universitat de Barcelona/Eumo Editorial, XXX. 